\title{
CALCULATING THE DEVIATION OF VERTICAL STEEL TANK WALLS FROM VERTICALITY
}

The work is devoted to the processing of geodetic instrumental observations included in technical inspection of vertical steel tanks aimed to determine their geometric parameters. The research presents the algorithm for calculating the center of the vertical steel tank based on the data collected through instrumental observations performed on a real object. The developed algorithm allows to determine the center of the circle circumscribing a structure or an object of round form using the spatial coordinates of this object, in particular, even in the case of the absence of the data on the whole perimeter of an object. The deviations of the walls of the vertical steel tank from verticality were calculated by detecting radial displacements. In this paper, the calculation of the tank's bank was executed using the determination of the directing vector of the approximating line describing the axis of the tank, which made it possible to obtain the corrected numbers of radial displacements. An analysis of the accuracy of determining this approximating line was carried out.

Keywords: VST, vertical steel tank, geometric parameters, technical inspection, expert examination, center of the circle, bank.

В. С. Старовєров, канд. техн. наук, професор,

К. О. Нікітенко, асп. кафедри інженерної геодезії Київський національний університет будівництвв і архітектури

\section{РОЗРАХУНОК ПАРАМЕТРІВ АЕРОФОТОЗЙОМКИ ПІД ЧАС ПАСПОРТИЗАЦІї МАГІСТРАЛЬНИХ ТРУБОПРОВОДІВ}

У статті розглянуто особливості розрахунку параметрів аерофотозйомки з безпілотних літальних апаратів (БПЛА) під час паспортизації магістральних трубопроводів. Викладено спосіб оперативного оцінювання якості аерофотозйомки з безпілотних літальних апаратів.

У роботі проаналізовано переваги аерофотозйомки об'єктів магістральних трубопроводів та представлені параметри літака на маршруті. Крім того, встановлено порядок виконання аерофотознімальних робіт для цілей картографування. Необхідність аерофотознімання пояснюється тим, що за багато років в Украӥні накопичився величезний масив інформачії про діючі магістральні трубопроводи-газопроводи. Однак иі дані частково не впорядковані, а частково втрачені, щуо не дає можливості оперативно скористатися ними в разі аварійної ситуації або обтрунтовано планувати роботи з реконструкиії.

(C) В.С. Старовєров, К.О. Нікітенко, 2019 
Запропонований розрахунок параметрів аерофотозйомки об'єкта орієнтований на потреби технічного обслуговування $i$ забезпечення иілісності та безпеки трубопровідної системи в процесі ї̈ експлуатаџії.

Ключові слова: аерофотозйомка, безпілотні літальні апарати (БПЛА), паспортизація, продуктивність цฺифрової камери.

Вступ. Розрахунок параметрів аерофотозйомки - дуже важливий етап підготовчих робіт. Правильно розраховані параметри дають змогу збільшити площу, що покривається за один політ БПЛА, за більш високої якості фотоматеріалів, застосовуваних в картографо-геодезичних, землевпорядних i кадастрових роботах. Аерофотозйомка дає об'єктивні відомості і можливість виявляти об'єкти місцевості, не помітні під час візуального обстеження. Для підтримки паспортизації магістральних трубопроводів на сучасному рівні необхідним є системне оновлення наявних картографічних матеріалів. Під час локального оновлення картографічних матеріалів доцільно використовувати надлегкі БПЛА масою до 5 кг [1]. Такі БПЛА мають високу мобільність і відносно низьку ціну.

Аерофотозйомка об'єктів магістральних трубопроводів має ряд незаперечних «плюсів»:

- здатність охопити всю площу ділянки;

- можливість високої деталізації;

- велике розширення знімків, чіткість і високу якість.

Перевагою зйомки можна вважати й те, що з висоти «пташиного польоту» зображення виявляються набагато змістовнішими, ніж знімки, отримані в результаті застосування традиційного методу, адже в цьому випадку в об'єктив потрапляє не тільки об'єкт, а й територія навколо нього. Розрахунок параметрів аерофотозйомки викладено у відповідних нормативних документах. Аерофотозйомка 3 малих безпілотних літальних апаратів має ряд особливостей: перевищення допустимих кутів нахилу знімків, недотримання прямолінійності траєкторії польоту для забезпечення необхідного перекриття між знімками, висока частота фотографування і як наслідок надлишок кадрів. Існує методика розрахунку деяких параметрів аерофотозйомки 3 БПЛА, таких як висота фотографування, відстань між маршрутами і між центрами фотографування на маршруті .

Отже, актуальним завданням є визначення параметрів аерофотозйомки для паспортизації магістральних трубопроводів.

Аналіз досліджень і публікацій. Останніми роками з'явилася велика кількість публікацій про використання безпілотних літальних апаратів для вирішення топографічних завдань, авторами яких є М.Д. Мітін, Д.Б. Нікольский, А.С. Костюк та багато інших провідних українських i російських учених i фахівців приватних організацій.

Результати виконаних експериментальних досліджень і практичних робіт свідчать про те, що аерофотозйомка з БПЛА здатна успішно замінити традиційну аерофотозйомку і наземні методи збору просторових даних з метою створення й оновлення топографічних і кадастрових планів великих масштабів [2]. Отримані в 
результаті безпілотної аерофотозйомки цифрові ортофотоплани 3 наповненням векторними даними і прив'язкою до зовнішніх баз даних використовують як кінцевий продукт в геоінформаційних системах (ГІС), а також як планову основу створення цифрових топографічних планів і карт.

Постановка завдання. Метою роботи $\epsilon$ розрахунок параметрів аерофотозйомки для паспортизації магістральних трубопроводів.

Основна частина. Для виконання аерофотозйомки потрібно:

- вибрати аерофотознімальну апаратуру, маса якої не перевищує 1 кг ;

- дібрати камеру для цілей аерофотозйомки;

- обчислити продуктивність кожної камери;

- розрахувати відстань між маршрутами аерофотозйомки;

- встановити параметри втримання літака на маршруті.

Функціональне призначення паспортизації магістральних трубопроводів полягає в оперативній видачі адміністративному і експлуатаційному персоналу набору даних про задані об'єкти системи або системи загалом. Наприклад, за запитом «надати всю інформацію про ділянку трубопроводу на певному пікеті або в певній географічній точці» 3 паспорта будуть вилучені у формі звіту потрібні дані (наприклад, заводський номер, діаметр, товщина стінки труби, марка стали, тип ізоляції, технічні умови, завод-виробник та ін.; хто, з якою метою і якими методами виконував обстеження; які дефекти і де були виявлені і який ступінь їх небезпеки; які роботи з технічного обслуговування і ремонту були виконані; 3 яким тиском працювала ділянка трубопроводу тощо) та аерознімок ділянки (рис.1).

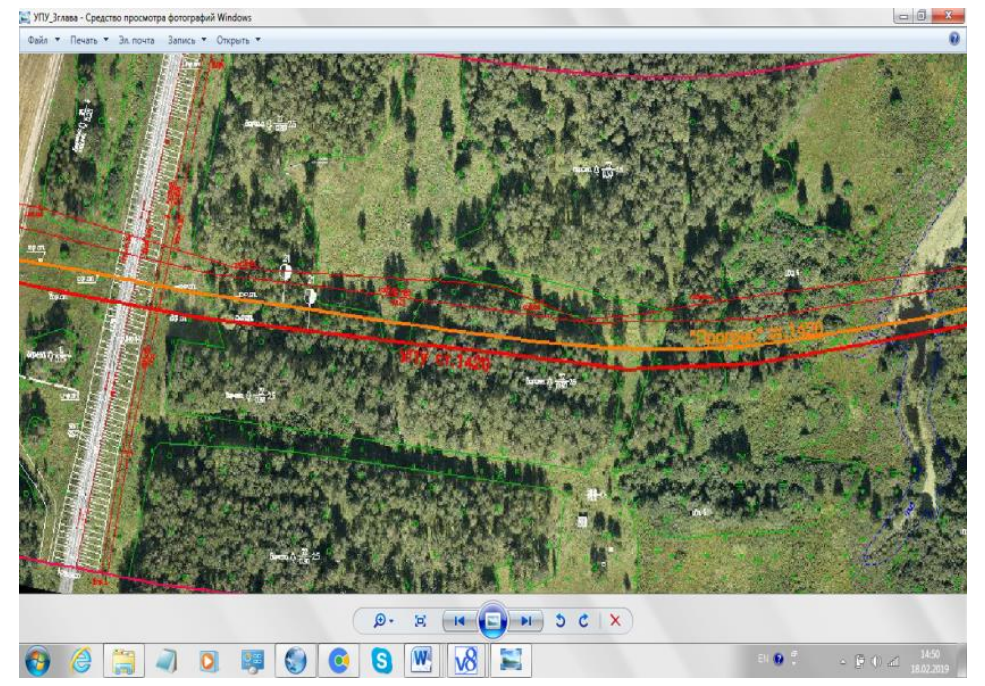

Рис.1 Аерознімок з кадастровою картою ділянки

Таким чином, для будь-якої ділянки може бути отриманий опис «фактичного життєвого циклу».

Вибір фотокамер для цілей аерофотозйомки грунтується на аналізі таких характеристик: роздільна здатність знімків, фізичний розмір матриці, величина кута захоплення, вага камери і їі вартість.

Оскільки в попередніх статтях [3; 4] розглянуто характеристики сучасних цифрових фотокамер, треба лише обчислити продуктивність камери. 
Продуктивність цифрової камери для аерофотознімання виражається в потрібній кількості знімків на один квадратний кілометр (км²) території. Високою буде продуктивність камери 3 меншою кількістю знімків. Для розрахунку кількості знімків на 1 км² треба обчислити оптимальну відстань між маршрутами аерофотозйомки i центрами фотографування на маршруті. Відстань між маршрутами аерофотозйомки i центрами фотографування на маршруті визначають 3 урахуванням точності ГЛОНАCC / GPS-навігації і особливостей БПЛА [5]. Параметри утримання літака на маршруті такі:

- поперечне зміщення від осі маршруту - \pm 10 м;

- утримування БПЛА на запроектованої висоті - \pm 15 м;

- відстань від запроектованого центру фотографування до точки спрацьовування затвора фотоапарата - \pm 5 м;

- зміна кута нахилу БПЛА на маршруті між двома знімками - 10 \%;

- зміна кута тангажу БПЛА на маршруті між двома знімками - $6^{\circ}$.

Висота аерофотозйомки залежить від масштабу створюваного фотоплану. Величина крайнього пікселя знімка на місцевості не повинна перевищувати 0,07 мм в масштабі створюваного фотоплану. Для розрахунку продуктивності фотокамер слід визначити максимально допустиму висоту фотографування за заданого масштабу створюваного фотоплану.

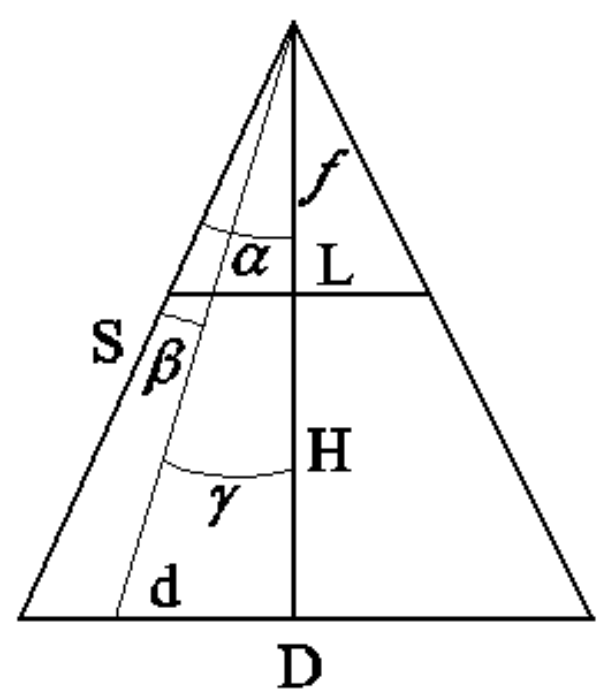

Схему зв'язку розміру крайнього пікселя знімка 3 місцевістю наведено на рис. 2, де $f$ - фокусна відстань камери в еквіваленті для 35 мм кадра; L - довжина половини діагоналі матриці, для 35-мм кадра вона становитиме 21,6 мм; $\mathrm{H}$ - висота фотографування під час аерофотозйомки; D довжина половини діагоналі знімка на місцевості.

Розрахунок роздільної здатності знімка слід виконувати для пікселів, найбільш віддалених від центра кадра.

Рис. 2. Зв'язок розміру пікселя знімка 3 місцевістю

3 рис. 2 випливає:

$$
\begin{aligned}
\mathrm{S}= & \frac{\mathrm{d} \times \cos (\beta-\alpha)}{\sin \beta} ; \\
& H_{\max }=S \times \cos \alpha .
\end{aligned}
$$

Максимально допустиму висоту аерофотозйомки обчислюють за формулою (2), кут $\alpha$ розраховують, залежно від величини фокусної відстані камери і розміру кадра.

Для розрахунку відстані між маршрутами необхідно забезпечити 30\% поперечне перекриття, за формулою обчислюють половину поперечного кута захоплення камери, де $L_{\text {попереч }}$ - половина ширини кадра: 


$$
\gamma=\operatorname{arcctg}\left(\frac{\mathrm{f}}{\mathrm{L}_{\text {попереч }}}\right) .
$$

3 урахуванням похибки барометричного датчика визначаємо висоту польоту:

$$
H_{\text {пол }}=H_{\max }-20 \mathrm{M} .
$$

Половину ширини захоплення місцевості камерою обчислюємо за формулою:

$$
D=H_{\text {пол }} \times \operatorname{tg} \gamma .
$$

Відстань між маршрутами в ідеальних умовах обчислюється за формулою:

$$
A_{\text {ум }}=2 \times P_{\text {ум }} \times D \text {, }
$$

де $P_{\mathrm{yм}}=0,7$ за $30 \%$ поперечного перекриття знімків.

Оптимізація вибору цифрової фотокамери для цілей аерофотозйомки дає змогу майже в два рази підвищити продуктивність зйомки за один політ, отже, зменшити час на виконання робіт і кількість посадок на непідготовлену площадку, що мінімізує ймовірність поломки безпілотного апарата.

Виконавши розрахунок для Supercam S250, оснащеного двочастотним приймачем, камерою Sony Alpha ILCE-6000 з матрицею 4224x3168 пікселів, отримали: $H_{\max }=467 \mathrm{~m} ; H_{\text {пол }}=447 \mathrm{~m} ; D=86 \mathrm{м}$.

Правильно розраховані параметри дають можливість збільшити площу, що покривається за один політ. Нині розрахунок параметрів виконується автоматично за допомогою спеціальних програм, таких як Digitals, Mapinfo, Bentley Map тощо. Застосування програм сприяє швидкому плануванню маршрутів польоту, для складання проекту досить задати параметри зйомки, виділити робочу ділянку i вказати напрямок маршрутів. Всі параметри побудови проекту відображаються i зберігаються в таблицях, завдяки цьому можна редагувати маршрути безпосередньо на об'єкті робіт і завантажувати їх в навігаційну програму.

Висновки. Комплексне вирішення проблем, пов'язаних 3 вибором фотокамер, розрахунком параметрів й оперативною оцінкою якості аерофотозйомки дає можливість виконати паспортизацію магістральних трубопроводів за допомогою БПЛА дуже якісно та швидко. Розрахунок параметрів проектування аерофотозйомки 3 БПЛА істотно скорочує час виконання аерофотознімальних робіт і підвищити якість матеріалів.

\section{СПИСОК ЛІТЕРАТУРИ}

1. Скубиев С.И. Инновационная деятельность Государственного университета по землеустройству / С. И. Скубиев // Землеустройство, кадастр и мониторинг земель. - 2009. - Вип. № 9. - С. 50.

2. Митин М.Д. Современные тенденции развития отрасли беспилотных летательных аппаратов / М.Д. Митин, Д.Б. Никольский // Геоматика.- 2013. №4. - C. 27-31.

3. Старовєров В.С. Оцінка точності дистанційної діагностики трубопроводу з застосуванням БПЛА серії supercam / В.С. Старовєров, К.О. Нікітенко // Інженерна геодезія - 2018. - Вип. 65. - С. 25-32.

4. Чибіряков В.К. Застосування методів дистанційного контролю для моніторингу магістральних нафтопроводів і газопроводів / В.К. Чибіряков, 
В.С. Старовєров, К.О. Нікітенко // Містобудування та територіальне планування.2017. - Вип. 63. - С. 475-478.

5. Использование БПЛА в целях картографического мониторинга / Информационно-аналитический журнал о землеустройстве, геодезии, картографии и навигации. [Электронный ресурс] - Режим доступа: http://www.myshared.ru/slide/430644.- Назва з екрана. - Дата звернення 27.12.2017.

6. Инструкция по фотограмметрическим работам при создании цифровых топографических карт и планов. - М.: Федеральная служба геодезии и картографии России, 2002. - 100 с.

\section{REFERENCES}

1. Skybiev S.I. (2009). Inovacionnaya deyatelnost Gosudarstvennogo Universiteta po zemleustrojstvu [Innovative activities of the State University for Land Management]. Land management, cadastre and land monitoring, N9,50 [in Russian].

2. Mitin M.D., Nikolskij D.B. (2013). Sovremennue tendecii razvitiya otrasli bespilotnuh letatelnuh apparatov [Current trends in the development of the industry of unmanned aerial vehicles]. Geomatics N4-27-31 [in Russian].

3. Staroverov V.S., Nikitenko K.A. (2018). Ocinka tochnosti dustancijnoi diagnostuku truboprovodu $\mathrm{z}$ zastosyvannyam bpl serii supercam [Estimation of the accuracy of the remote diagnostics of the pipeline with the use of a series of supercam ]. Inzhenerna heodeziia - Engineering geodesy, 65, 25-32 [in Ukrainian].

4. Chibiryakov V.K., Staroverov V.S., Nikitenko K.A. (2017). Zastosuvannya metodiv dystancijnogo kontrolu dlia monitoryngu magistralnyh naftoprovodiv i gazoprovodiv [Application of remote control methods for monitoring of main oil pipelines and gas pipelines]. Inzhenerna heodeziia - Engineering geodesy, 63, 475-479 [in Ukrainian].

5. Information and analytical magazine on land management, geodesy, cartography and navigation [Unmanned Systems]. (n.d.) unmanned.ru. Retrieved from http://www.myshared.ru/slide/430644. [in Russian].

6. Instrukciya po fotogrammetricheskim rabotam pri sozdanii cifrovuh topograficheskih kart I planov (2002). [Instructions for photogrammetric work when creating digital topographic maps and plans]. Moscow: Federal Service of Geodesy and Cartography of Russia. [in Russian].

\section{В.С. Староверов, К.А. Никитенко РАСЧЕТ ПАРАМЕТРОВ АЭРОФОТОСЬЕМКИ ПРИ ПАСПОРТИЗАЦИИ МАГИСТРАЛЬНЫХ ТРУБОПРОВОДОВ}

B cтатье рассмотрены особенности расчета параметров аэрофотосъемки с беспилотных летательных аппаратов (БПЛА) при паспортизации магистральных трубопроводов. Изложены способы оперативной оценки качества аэрофотосъемки с беспилотных летательных аппаратов.

В работе проанализированы преимущества аэрофотосъемки объектов магистральных трубопроводов и представлены параметры самолета на маршруте. Кроме того, установлен порядок проведения аэрофотосъемочных 


работ для иелей картографирования. Необходимость проведения

аэрофотосъемки заключается в том, что за многие годы в Украине накопился огромный массив информации о действующих магистральных трубопроводахгазопроводах. Однако эти данные частью неупорядочень, а частью потеряны, что не дает возможности оперативно воспользоваться ими в случае аварийной ситуации или обоснованно планировать работы по реконструкиии.

Предложенный расчет параметров аэрофотосъемки объекта ориентирован на нужды технического обслуживания и обеспечения целостности и безопасности трубопроводной системы в прочесе ее эксплуатации.

Ключевые слова: аэрофотосъемка, беспилотные летательные аппараты (БПЛА), паспортизащия, производительность циифровой камерьл.

V. Starovierov, K. Nikitenko CALCULATION OF PARAMETERS OF THE AEROPHOTOSYOMMIC IN PASSPOSITION OF MAGISTRAL PIPELINE

The article deals with the features of calculating the parameters of aerial photography from unmanned aerial vehicles (UAVs) with the certification of main pipelines. The method of operative estimation of the quality of aerial photography from the UAV is described. The paper analyzes the advantages of aerial photography for the objects of main pipelines and presents the parameters of the aircraft on the route. In addition, the procedure for conducting aerial photography works for mapping purposes has been established. The need for aerial photography is that for many years in Ukraine a huge amount of information has been accumulated over the existing trunk pipelinesgas pipelines. However, these data are disordered and partly lost, which does not allow them to be used promptly in the event of an emergency, or it is justified to plan reconstruction work. The proposed calculation of the parameters of aerial photography of the object is oriented on the needs of maintenance and ensuring the integrity and safety of the pipeline system during its operation.

Keywords: aerial photography, unmanned aerial vehicles (UAVs), certification, digital camera performance.

Надійшла до редакції

11.03.2019 